\title{
STUDY OF HISTOMORPHOLOGY AND IMMUNOHISTOCHEMICAL ANALYSIS IN BREAST NEOPLASM
}

\author{
Manish Kaushal1, Arvind Shukla², Pankaj Patil ${ }^{3}$
}

${ }^{1}$ Associate Professor, Department of Surgery, MGMMC and MY Hospital, Indore, Madhya Pradesh. ${ }^{2}$ Assistant Professor, Department of Surgery, MGMMC and MY Hospital, Indore, Madhya Pradesh. 3Junior Resident, Department of Surgery, MGMMC and MY Hospital, Indore, Madhya Pradesh.

\begin{abstract}
BACKGROUND parameter with the strongest prognostic significance is hormone receptor status.

Aims and Objectives-

1. Occurrence of ER, PR and HER-2/neu in post-surgical histological specimen.

2. Expression of ER, PR and HER-2/neu receptors as per staging in carcinoma breast.

3. To co-relate histomorphological variants with immunohistochemistry.
\end{abstract}

ABSTRACT

Carcinoma of the breast is the most common malignant tumour and the most common cause of death from carcinoma in females all over the world.(1) The important pathological prognostic factors in invasive breast carcinoma include patient's age, tumour size, lymph node metastasis, nuclear grade, histological grade, histological type, hormone receptor status and HER-2/neu.(2) A single

\section{MATERIALS AND METHODS}

A hospital-based, prospective, observational study was conducted at Department of Surgery, MGM Medical College and MY Hospital, Indore. A total of 50 diagnosed carcinoma breast cases coming to our hospital were taken into study after informed consent. Detailed history was taken from patients and a biopsy specimen was taken from all patients. Gross examination pertaining to overall size of the specimen, nipple and areola, tumour size, margin status and nodal status were carefully studied. The tissue was processed for routine histopathological examination and stained with haematoxylin and eosin. The slides were then stained with ER, PR and HER$2 /$ neu antibodies.

\section{RESULTS}

Mean age of the study subjects was 54.32 years, while age at menarche and menopause was 13.12 years and 44.61 years respectively. Most common type of carcinoma seen in the present study was invasive ductal carcinoma (90\%). Out of the total 50 cases, $20 \%$ and $42 \%$ were in stage I and II respectively, while $36 \%$ and $2 \%$ were in stage III and IV. Prevalence of positive oestrogen receptor, progesterone receptor and HER-2/neu status was seen in 52\%, 48\% and $24 \%$ cases respectively. No association was observed between age at diagnosis and parity with positive hormonal status. A significant association was observed between increasing tumour size and LN status with positive HER-2/neu and ER and PR negative status ( $<<0.05)$. Out of the 19 cases of stage III/ IV approx. $31.6 \%$ are ER and PR+, while out of 31 cases in stage I/ II $64.5 \%$ were ER and PR positive ( $p<0.01$ ). Similarly, $22.6 \%$ cases of stage I/ II were HER-2/neu positive as compared to $21.05 \%$ of stage III and IV (p-0.27).

\section{CONCLUSION}

The frequency of carcinoma of breast is high in post-menopausal group. The most common tumour pathology found in the study was Ductal Carcinoma. Definitive prognostic correlation was found with ER and PR receptors. HER-2/neu expression was high in advanced diseases like axillary node positive patients. The clinical importance of these prognostic markers in the management of breast cancer in clinical practice is strongly recommended.

\section{KEYWORDS}

ER, PR, HER-2/NEU.

HOW TO CITE THIS ARTICLE: Kaushal M, Shukla A, Patil P. Study of histomorphology and immunohistochemical analysis in breast neoplasm. J. Evolution Med. Dent. Sci. 2018;7(08):1044-1047, DOI: 10.14260/jemds/2018/238

\section{BACKGROUND}

Carcinoma of the breast is the most common malignant tumour and the most common cause of death from carcinoma in females all over the world.

The important pathological prognostic factors in invasive breast carcinoma include patient's age, tumour size, lymph node metastasis, nuclear grade, histological grade,

'Financial or Other Competing Interest': None.

Submission 11-10-2017, Peer Review 05-02-2018,

Acceptance 12-02-2018, Published 19-02-2018.

Corresponding Author:

Dr. Arvind Shukla,

\#335, BC, Scheme 140,

Pipliyahana, Indore-452016.

E-mail: drshuklaarvind@gmail.com

DOI: $10.14260 /$ jemds $/ 2018 / 238$ histological type, hormone receptor status and HER-2/neu. A single parameter with the strongest prognostic significance is hormone receptor status.[3] Intracellular steroid-hormone receptor proteins, primarily oestrogen receptor (ER) and progesterone receptor (PR) have received intensive study, both as indicator of prognosis and as guide to hormone therapy.[4]

The present study was thus aimed to evaluate the prevalence and to understand the role of ER, PR and HER-2 status in choice of treatment for further management in patients of breast carcinoma.

\section{MATERIALS AND METHODS}

A hospital-based prospective observational study was conducted at Department of Surgery, MGM Medical College and MY Hospital, Indore. A total of 50 diagnosed carcinoma 
breast cases coming to our hospital were taken into study after informed consent. Detailed history was taken from patients and a biopsy specimen was taken from all patients. Gross examination pertaining to overall size of the specimen, nipple and areola, tumour size, margin status and nodal status were carefully studied. The tissue was processed for routine histopathological examination and stained with Haematoxylin and eosin. The slides were then stained with ER, PR and HER$2 /$ neu antibodies.

\section{Statistical Methods Applied}

Data were statistically described in terms of mean $( \pm S D)$, frequencies (number of cases) and percentages when appropriate. Data were tested first for normal distribution by Kolmogorov-Smirnov test. Comparison of quantitative variables between the study groups was done using student's ' $\mathrm{t}$ ' test for independent samples if normally distributed. MannWhitney $U$ test was used for non-normally distributed quantitative data. For comparing categorical data, Chi-square test was performed. Exact test was used instead when the expected frequency was less than 5. For qualitative comparison of tables over $2 \times 2$ dimensions like TNM staging, $p$-trend value was calculated. A probability value ( $p$ value) less than 0.05 was considered statistically significant. All statistical calculations were done using computer programs Microsoft Excel 2007 (Microsoft Corporation, NY, USA) and SPSS (Statistical Package for the Social Sciences, SPSS Inc., Chicago, IL, USA) version 21.

\section{Inclusion Criteria}

1. Clinically diagnosed carcinoma breast in females above 30 years of age.

2. Patients who gave written informed consent.

\section{Exclusion Criteria}

1. Those who have undergone any chemoreduction treatment.

2. Patients already treated for contralateral breast cancer.

3. Patients not willing to give written consent.

\section{RESULTS}

1. Mean age of the study subjects was 54.32 years, while age at menarche and menopause was 13.12 years and 44.61 years respectively.

2. Most common type of carcinoma seen in present study was invasive ductal carcinoma (90\%).

3. Out of the total 50 cases $20 \%$ and $42 \%$ were in stage I and II respectively, while $36 \%$ and $2 \%$ were in stage III and IV.

4. Prevalence of positive oestrogen receptor, progesterone receptor and HER-2/neu status was seen in 52\%, 48\% and $24 \%$ cases respectively.

5. No association was observed between age at diagnosis and parity with positive hormonal status.

6. A significant association was observed between increasing tumour size and LN status with positive HER$2 /$ neu and ER and PR negative status ( $\mathrm{p}<0.05)$.

7. Out of 19 cases of stage III/ IV, approx. $31.6 \%$ are ER and $\mathrm{PR}+$, while out of 31 cases in stage I/II $64.5 \%$ were ER and PR positive ( $p<0.01$ ). Similarly, $22.6 \%$ cases of stage I/II were HER-2/neu positive as compared to $21.05 \%$ of stage III and IV (p-0.27).

\section{DISCUSSION}

A hospital-based prospective observational study was conducted at Dept. of Surgery of a tertiary care hospital with the objective of finding the correlation of ER, PR and HER$2 /$ neu incidence with other prognostic factors like age, parity, tumour size and lymph node status. A total of 50 operated cases of carcinoma breast who fulfilled the selection criteria and gave voluntary consent to be a part of the study were enrolled in this study. Following observations were made during the study-

1. Over half of the study subjects $(60 \%)$ were between 40 60 years of age, while $12 \%$ were below 40 years of age.

2. Mean age of the study subjects was 54.32 years, while age at menarche and menopause was 13.12 years and 44.61 years respectively.

3. Most of the cases were multipara (94\%).

4. About three-fourth of the study subjects belonged to postmenopausal, while $16 \%$ were pre-menopausal.

5. Family history of carcinoma breast to first-degree relative was given by $18 \%$ cases.

6. Both sides were equally involved in the present study. No case of bilateral carcinoma was seen in our study.

7. Most common type of carcinoma seen in the present study was Invasive ductal carcinoma (90\%). Other cases were of malignant phyllodes (4\%), mucinous carcinoma (4\%) and papillary carcinoma (2\%).

8. About half of the cases were in 'T' stage 2, while lymph node involvement was seen in $42 \%$ cases. Metastasis was observed in $2 \%$ cases.

9. Out of the total 50 cases $20 \%$ and $42 \%$ were in stage I and II respectively, while $36 \%$ and $2 \%$ were in stage III and IV.

10. Prevalence of positive oestrogen receptor, progesterone receptor and HER-2/neu status was seen in 52\%, 48\% and $24 \%$ cases respectively.

11. No association was observed between age at diagnosis and positive oestrogen receptor, progesterone receptor and HER-2/neu status ( $p>0.05$ ).

12. No association was observed between parity and positive oestrogen receptor, progesterone receptor and HER$2 /$ neu status $(\mathrm{p}>0.05)$

13. A significant association was observed between increasing tumour size with positive HER-2/neu positive status and ER and PR negative status $(\mathrm{p}<0.05)$.

14. Out of 29 cases with negative lymph node status, positive oestrogen and progesterone receptor status was seen in $19(65.5 \%)$ and 17 (58.6\%), while out of 21 cases with positive LN status $66.7 \%$ each were ER and PR negative ( $\mathrm{p}<0.05$ ). Similarly, out of the 29 cases with negative lymph node status $86.2 \%$ were HER-2/neu negative and out of 21 positive cases, $38.1 \%$ were HER-2/neu positive $(\mathrm{p}<0.05)$.

15. Out of the 19 cases of stage III/ IV approx. $31.6 \%$ are ER and PR+, while out of 31 cases in stage I/II 64.5\% were ER and PR positive ( $\mathrm{p}<0.01$ ). Similarly, $22.6 \%$ cases of stage I/II were HER-2/neu positive as compared to $21.05 \%$ of stage III and IV (p-0.27). 


\begin{tabular}{|c|c|c|c|c|c|}
\hline \multicolumn{6}{|c|}{ Age at Diagnosis (Yrs.) } \\
\hline Variables & Results & $\mathbf{N}$ & Mean & SD & $\begin{array}{c}\mathrm{P}- \\
\text { value }\end{array}$ \\
\hline \multirow{2}{*}{ ER } & Negative & 24 & 53.58 & 10.23 & \multirow[b]{2}{*}{0.54} \\
\hline & Positive & 26 & 54.90 & 11.57 & \\
\hline \multirow{2}{*}{ PR } & Negative & 26 & 54.68 & 11.93 & \multirow{2}{*}{0.69} \\
\hline & Positive & 24 & 53.81 & 9.75 & \\
\hline \multirow{2}{*}{ HER-2/Neu } & Negative & 38 & 54.91 & 11.58 & \multirow[b]{2}{*}{0.3} \\
\hline & Positive & 12 & 52.25 & 8.35 & \\
\hline$T c$ & $\begin{array}{r}\text { on of Ho } \\
\text { Pres }\end{array}$ & 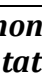 & ecep & with & \\
\hline
\end{tabular}

No association was observed between age at diagnosis and positive oestrogen receptor, progesterone receptor and HER$2 /$ neu status $(\mathrm{p}>0.05)$

\begin{tabular}{|c|c|c|c|c|c|}
\hline \multicolumn{7}{|c|}{ Age at Menarche (Yrs.) } \\
\hline Variables & Results & N & Mean & SD & P-value \\
\hline \multirow{2}{*}{ ER } & Negative & 24 & 13.43 & 3.23 & \multirow{2}{*}{0.79} \\
\cline { 2 - 6 } & Positive & 26 & 13.01 & 3.10 & \\
\hline \multirow{2}{*}{ PR } & Negative & 26 & 12.96 & 2.39 & \multirow{2}{*}{0.61} \\
\cline { 2 - 5 } & Positive & 24 & 13.38 & 3.65 & \\
\hline \multirow{2}{*}{ HER-2/Neu } & Negative & 38 & 13.21 & 3.54 & \multirow{2}{*}{0.48} \\
\cline { 2 - 5 } & Positive & 12 & 12.49 & 2.44 & \\
\hline \multicolumn{7}{|c|}{ Table 2. Association of Hormonal Receptors with } \\
Age at Menarche \\
\hline
\end{tabular}

No association was observed between age at menarche and positive oestrogen receptor, progesterone receptor and HER-2/neu status ( $p>0.05)$.

\begin{tabular}{|c|c|c|c|c|c|}
\hline \multicolumn{7}{|c|}{ Age at Menopause (Yrs.) } \\
\hline Variables & Results & N & Mean & SD & P-value \\
\hline \multirow{2}{*}{ ER } & Negative & 24 & 44.58 & 5.18 & \multirow{2}{*}{0.891} \\
\cline { 2 - 5 } & Positive & 26 & 44.79 & 5.56 & \\
\hline \multirow{2}{*}{ PR } & Negative & 26 & 44.12 & 5.09 & \multirow{2}{*}{0.67} \\
\cline { 2 - 5 } & Positive & 24 & 44.91 & 5.77 & \\
\hline \multirow{2}{*}{ HER-2/Neu } & Negative & 38 & 44.77 & 5.91 & \multirow{2}{*}{0.59} \\
\cline { 2 - 5 } & Positive & 12 & 43.81 & 5.32 & \multirow{5}{*}{ Menopause } \\
\hline \multicolumn{7}{|c|}{ Table 3. Association of Hormonal Receptors with Age at } \\
\hline
\end{tabular}

No association was observed between age of menopause and positive oestrogen receptor, progesterone receptor and HER-2/neu status ( $\mathrm{p}>0.05)$.

\begin{tabular}{|c|c|c|c|c|c|c|}
\hline \multirow{2}{*}{ Parity } & \multicolumn{2}{|c|}{ ER } & \multicolumn{2}{|c|}{ PR } & \multicolumn{2}{|c|}{ HER-2/NEU } \\
\hline & \begin{tabular}{|l} 
Negative \\
\end{tabular} & Positive & Negative & Positive & Negative & Positive \\
\hline \multirow{2}{*}{ Multi } & 22 & 25 & 24 & 23 & 35 & 12 \\
\hline & $46.8 \%$ & $53.2 \%$ & $51.1 \%$ & $48.9 \%$ & $74.5 \%$ & $25.5 \%$ \\
\hline \multirow{2}{*}{ Primi } & 2 & 1 & 2 & 1 & 3 & 0 \\
\hline & $66.7 \%$ & $33.3 \%$ & $66.7 \%$ & $33.3 \%$ & $100.0 \%$ & $0.0 \%$ \\
\hline Total & 24 & 26 & 26 & 24 & 38 & 12 \\
\hline \begin{tabular}{|l} 
P-value \\
\end{tabular} & \multicolumn{2}{|c|}{0.345} & \multicolumn{2}{|c|}{0.489} & \multicolumn{2}{|c|}{0.664} \\
\hline
\end{tabular}

No association was observed between parity and positive oestrogen receptor, progesterone receptor and HER-2/neu status ( $p>0.05$ ) and HER-2/neu status ( $p>0.05)$.

\begin{tabular}{|c|c|c|c|c|c|c|}
\hline \multirow{2}{*}{$\begin{array}{c}\text { Tumour } \\
\text { Size } \\
\text { (TNM) }\end{array}$} & \multicolumn{2}{|c|}{ ER } & \multicolumn{2}{|c|}{ PR } & \multicolumn{2}{|c|}{ HER-2/Neu } \\
\hline & Negative & Positive & Negative & Positive & Negative & Positive \\
\hline \multirow[b]{2}{*}{0} & 0 & 3 & 1 & 2 & 3 & 0 \\
\hline & $0.0 \%$ & $100.0 \%$ & $33.3 \%$ & $66.7 \%$ & $100.0 \%$ & $0.0 \%$ \\
\hline \multirow{2}{*}{1} & 2 & 5 & 2 & 5 & 7 & 0 \\
\hline & $28.6 \%$ & $71.4 \%$ & $28.6 \%$ & $71.4 \%$ & $100.0 \%$ & $0.0 \%$ \\
\hline \multirow{2}{*}{2} & 11 & 15 & 12 & 14 & 22 & 4 \\
\hline & $42.3 \%$ & $57.7 \%$ & $46.2 \%$ & $53.8 \%$ & $84.6 \%$ & $15.4 \%$ \\
\hline \multirow{2}{*}{3} & 3 & 1 & 3 & 1 & 2 & 2 \\
\hline & $75.0 \%$ & $25.0 \%$ & $75.0 \%$ & $25.0 \%$ & $50.0 \%$ & $50.0 \%$ \\
\hline \multirow{2}{*}{4} & 8 & 2 & 8 & 2 & 4 & 6 \\
\hline & $80.0 \%$ & $20.0 \%$ & $80.0 \%$ & $20.0 \%$ & $40.0 \%$ & $60.0 \%$ \\
\hline Total & 24 & 26 & 26 & 24 & 38 & 11 \\
\hline P-value & \multicolumn{2}{|c|}{$<0.05$} & \multicolumn{2}{|c|}{$<0.05$} & \multicolumn{2}{|c|}{$<0.05$} \\
\hline
\end{tabular}

A significant association was observed between increasing tumour size with positive HER-2/neu positive status and ER and PR negative status $(\mathrm{p}<0.05)$.

\begin{tabular}{|c|c|c|c|c|c|c|}
\hline \multirow{2}{*}{$\begin{array}{c}\text { Lymph } \\
\text { Node } \\
\text { Status }\end{array}$} & \multicolumn{2}{|l|}{ ER } & \multicolumn{2}{|c|}{ PR } & \multicolumn{2}{|c|}{ HER-2/Neu } \\
\hline & Negative & $\begin{array}{c}\text { Posi } \\
\text { tive }\end{array}$ & Negative & Positive & Negative & Positive \\
\hline \multirow[b]{2}{*}{ Negative } & 10 & 19 & 12 & 7 & 25 & 4 \\
\hline & $34.5 \%$ & $\begin{array}{c}65.5 \\
\%\end{array}$ & $41.4 \%$ & $58.6 \%$ & $86.2 \%$ & $13.8 \%$ \\
\hline \multirow[b]{2}{*}{ Positive } & 14 & 7 & 14 & 7 & 10 & 8 \\
\hline & $66.7 \%$ & $\begin{array}{c}33.3 \\
\%\end{array}$ & $66.7 \%$ & $33.3 \%$ & $61.9 \%$ & $38.1 \%$ \\
\hline Total & 24 & 26 & 26 & 24 & 38 & 12 \\
\hline P-value & \multicolumn{2}{|c|}{$<0.01$} & \multicolumn{2}{|c|}{$<0.05$} & \multicolumn{2}{|c|}{$<0.05$} \\
\hline \multicolumn{7}{|c|}{$\begin{array}{c}\text { Table 6. Association of Hormonal Receptors with Lymph } \\
\text { Node Involvement }\end{array}$} \\
\hline
\end{tabular}

Out of 29 cases with negative lymph node status, positive oestrogen and progesterone receptor status was seen in 19 $(65.5 \%)$ and 17 (58.6\%), while out of 21 cases with positive LN status $(66.7 \%)$ each were ER and PR negative ( $<0.05)$. Similarly, out of 29 cases with negative lymph node status, $86.2 \%$ were HER-2/neu negative and out of 21 positive cases $38.1 \%$ were HER-2/neu positive $(\mathrm{p}<0.05)$.

\begin{tabular}{|c|c|c|c|c|c|c|}
\hline \multirow{2}{*}{$\begin{array}{l}\text { TNM } \\
\text { Stage }\end{array}$} & \multicolumn{2}{|c|}{ ER } & \multicolumn{2}{|c|}{ PR } & \multicolumn{2}{|c|}{ HER-2/Neu } \\
\hline & Negative & Positive & Negative & Positive & Negative & \begin{tabular}{|l|} 
Positive \\
\end{tabular} \\
\hline \multirow{2}{*}{ I } & 6 & 4 & 7 & 3 & 8 & 2 \\
\hline & $60.0 \%$ & $40.0 \%$ & $70.0 \%$ & $30.0 \%$ & $80.0 \%$ & $20.0 \%$ \\
\hline \multirow{2}{*}{ II } & 5 & 16 & 6 & 15 & 16 & 5 \\
\hline & $23.8 \%$ & $76.2 \%$ & $28.6 \%$ & $71.4 \%$ & $76.2 \%$ & $23.8 \%$ \\
\hline \multirow{2}{*}{ III } & 12 & 6 & 12 & 6 & 15 & 3 \\
\hline & $66.7 \%$ & $33.3 \%$ & $66.7 \%$ & $33.3 \%$ & $83.3 \%$ & $16.7 \%$ \\
\hline \multirow{2}{*}{ IV } & 1 & 0 & 1 & 0 & 0 & 1 \\
\hline & $100.0 \%$ & $0.0 \%$ & $100.0 \%$ & $0.0 \%$ & $0.0 \%$ & $100.0 \%$ \\
\hline Total & 24 & 26 & 26 & 24 & 39 & 11 \\
\hline P-value & \multicolumn{2}{|c|}{$<0.01$} & \multicolumn{2}{|c|}{$<0.01$} & \multicolumn{2}{|c|}{0.27} \\
\hline
\end{tabular}

Out of the 19 cases of stage III/IV approx. $31.6 \%$ are ER and PR+, while out of 31 cases in stage I/II 64.5\% were ER and PR positive $(\mathrm{p}<0.01)$.

\section{CONCLUSION}

The frequency of carcinoma of breast is high in postmenopausal group. The most common tumour pathology found in the study was Ductal Carcinoma. Definitive prognostic correlation was found with ER and PR receptors. 


\section{Jemds.com}

HER-2/neu expression was high in advanced diseases like axillary node positive patients.(5,6) The clinical importance of these prognostic markers in the management of breast cancer in clinical practice is strongly recommended.

\section{REFERENCES}

[1] Midulla C, Cenci M, De lorio P, et al. The value of fine needle aspiration cytology in the diagnosis of breast proliferative lesions. Anticancer Research 1995;15(6B):2619-22.

[2] Jemal A, Bray F, Center MM, et al. Global cancer statistics. CA Cancer Journal for Clinicians 2011;61(2):69-90.

\section{Original Research Article}

[3] Lin $\mathrm{CH}$, Lien HC, Hu FC, et al. Fractionated evaluation of immunohistochemical hormone receptor expression enhances prognostic prediction in breast cancer patients treated with tamoxifen as adjuvant therapy. J Zhejiang Univ Sci B 2010;11(1):1-9.

[4] Donegan WL. Tumor-related prognostic factors for breast cancer: CA Cancer Journal for Clinicians 1997;47(1):28-51.

[5] Mustafa IA, Bland KI. Physiologic effects of steroid hormones and postmenopausal hormone replacement on the female breast and breast cancer risk. Annals of Surgery 1998;228(5):638-51.

[6] Osborne CK. Steroid hormone receptors in breast cancer management. Breast Cancer Res Treat 1998;51(3):227-38. 